\title{
Validating and optimizing spot sampling of urine to estimate urine output with creatinine as a marker in dairy cows
}

\author{
C. Lee, ${ }^{*}$ D. L. Morris, and P. A. Dieter \\ Department of Animal Sciences, Ohio Agricultural Research and Development Center, The Ohio State University, Wooster 44691
}

\begin{abstract}
An experiment was conducted to validate and optimize the procedure of spot urine sampling with urinary creatinine as a marker to estimate urine outputs of dairy cows. Twelve lactating cows were used in a randomized complete block design. Cows were grouped and randomly assigned to 2 experimental diets: a corn silage-based diet and an alfalfa silage-based diet with supplemental potassium. The experiment lasted for 21 $\mathrm{d}$ and total collection (TC) of urine was conducted for the last $3 \mathrm{~d}$. Twelve spot samples of urine from individual cows were collected over a 3 -d period during TC to represent every 2 -h sampling in a 24 -h cycle. Creatinine excretion rate $(\mathrm{mg} / \mathrm{kg}$ of body weight per $\mathrm{d})$ was variable among cows from 16.7 to 34.5 with an average of 27.3. Creatinine concentrations of spot samples within cow were averaged to simulate urine samples obtained from various spot sampling frequencies (equally spaced 12, 6, 4, and 2 time points starting at feeding: $12 \mathrm{TP}$, $6 \mathrm{TP}, 4 \mathrm{TP}$, and $2 \mathrm{TP}$, respectively). Large diurnal variation of urinary creatinine concentration was observed within cow. Creatinine concentration was greater $(75$ vs. $65 \mathrm{mg} / \mathrm{dL}$ ) for $12 \mathrm{TP}$ compared with TC, resulting in underestimating (29.8 vs. $32.6 \mathrm{~kg} / \mathrm{d}$ ) urine outputs. When compared among $12 \mathrm{TP}, 6 \mathrm{TP}, 4 \mathrm{TP}$, and $2 \mathrm{TP}$, creatinine concentrations were different and urine outputs tended to be different for $2 \mathrm{TP}$ compared with $12 \mathrm{TP}$, $6 \mathrm{TP}$, and $4 \mathrm{TP}$. In addition, despite underestimation of urine output, a regression analysis indicated strong linear relationships between 12TP, 6TP, or 4TP and TC, suggesting that this technique can successfully identify the differences in urine outputs altered by dietary treatments. However, 4TP failed to detect statistical differences in urine outputs between a corn silage-based diet and the alfalfa silage-based diet with supplemental potassium, indicating that a spot urine sampling frequency of at least 6 was required to identify dietary effects on urine outputs. According to the pattern of
\end{abstract}

Received May 27, 2018.

Accepted September 12, 2018.

*Corresponding author: Lee.7502@osu.edu diurnal changes in urinary creatinine concentration, a spot sample at about $10 \mathrm{~h}$ after feeding may have potential to obtain a urine sample that is more representative (i.e., creatinine concentration) of TC urine compared with urine from multiple sampling frequencies. Overall, urinary creatinine as a marker with spot sampling of urine underestimated urine output. However, 12TP and $6 \mathrm{TP}$ were successful in identifying changes in urine outputs by dietary treatments.

Key words: creatinine, dairy cow, spot sampling, urine output

\section{INTRODUCTION}

Evaluating dietary nutrient utilization in dairy cows is important to formulate a ration to supply adequate nutrients. Deficient supply of dietary nutrients negatively affects production of cows (Lee et al., 2012), but excessive supply of nutrients increases nutrient excretion in manure, increasing environmental concerns (Olmos Colmenero and Broderick, 2006). Therefore, balance studies have been often conducted to determine the availability of dietary nutrients in dairy cows, which requires quantification of urine outputs. To quantify daily urine excretion, total collection (TC) of urine has been used as the gold standard method. However, TC is laborious and expensive and requires specific metabolism stalls to collect total urine and feces, which often limits the number of animals used in experiments. Therefore, a repeated Latin square design with a small number of cows has been used for TC of urine and feces and are likely appropriate to evaluate dietary effects on nutrient utilization (e.g., N retention). However, because experiments in a Latin square design are relatively short-term (e.g., 2 wk of dietary adaptation and $1 \mathrm{wk}$ sampling in each period), they may not be appropriate to evaluate dietary effects on production (Benefield et al., 2009; Weiss, 2012; Morris et al., 2018). Therefore, an indirect method to estimate urinary nutrient excretion as an alternative to TC has been used in a randomized block design (relatively long term) to examine dietary effects on nutrient utilization as well as production (Lee et al., 2012). 
As an alternative to TC, daily urine excretion has been estimated from urinary creatinine concentration using a spot urine sampling technique. The advantage of the indirect method is that more animals can be used, resulting in reliable examination of dietary effects on production as well as nutrient utilization (Broderick and Reynal, 2009; Lee et al., 2012). However, the accuracy of urine outputs estimated from urinary creatinine as a marker with spot urine sampling has been questioned by several studies (Shingfield and Offer, 1998; Andreen et al., 2017). Because of large diurnal variation of urinary creatinine concentration (de Groot and Aafjes, 1960; Shingfield and Offer, 1998), it has been generally assumed that multiple sampling of urine is required to minimize errors from the diurnal changes in urinary creatinine concentration. However, very few studies examined urinary creatinine as a marker to estimate urine outputs to confirm its accuracy regardless of various types of diets (Chizzotti et al., 2008; Tebbe and Weiss, 2018) and the procedure of spot urine sampling (i.e., frequency) has not been optimized. For example, although several studies have used the spot urine sampling technique, the sampling frequency of spot urine has varied from 1 to 8 sampling events (equally spaced sampling interval in a 24-h period; Olmos Colmenero and Broderick, 2006; Lee et al., 2012; Tebbe and Weiss, 2018).

The hypothesis of the study was that increasing the frequency of spot urine sampling will increase accuracy of estimating urine output. Also, we hypothesized that increasing frequency above an optimal number will not have an effect on the detection of a statistical difference in urine outputs caused by diets. Therefore, the current study was conducted to validate urinary creatinine as a marker and optimize the procedure of spot urine sampling to accurately estimate urine outputs of dairy cows.

\section{MATERIALS AND METHODS}

\section{Animals and Sample Collection}

The Ohio State University Institutional Animal Care and Use Committee approved animal care and all procedures used in the experiment. The experiment was carried out at the dairy research barn, the Ohio Agricultural Research and Development (Wooster). The experiment used 12 multiparous Holstein cows (average \pm SD at the beginning of the trial: DIM, 205 $\pm 49 \mathrm{~d}$; milk yield, $29.2 \pm 8.10 \mathrm{~kg} / \mathrm{d}$ ) in a randomized complete block design. Cows were grouped by DIM and milk yield, and cows in each group ( 2 cows per group; total 6 groups) were randomly assigned to 2 ex- perimental diets: CS, a diet with $49 \%$ corn silage (DM basis); AS-K, a diet with $48 \%$ alfalfa silage and high in byproduct (soybean hulls) and supplemental K. Diet ingredients and chemical composition were published in our companion paper (Morris et al., 2018). Briefly, the experimental diets were formulated to meet the requirements of all nutrients according to NRC (2001). The CS diet consisted of corn silage (49\% in dietary DM), grass hay (4\%), corn grain (16\%), soybean meal (16\%), soyhulls (8\%), AminoPlus (4\%; Ag Processing Inc., Omaha, NE), hydrolyzed tallow (0.5\%), and mineral and vitamin mix $(3 \%)$ and contained $16.5 \% \mathrm{CP}$ (DM basis), $33 \% \mathrm{NDF}, 26 \%$ starch, and $1.5 \% \mathrm{~K}$. The AS-K diet consisted of alfalfa silage ( $48 \%$ in dietary DM), grass hay $(4.5 \%)$, corn grain $(23 \%)$, soyhulls $(15.4 \%)$, AminoPlus $(4 \%)$, hydrolyzed tallow $(0.5 \%)$, potassium chloride (1.4\%), and mineral and vitamin mix $(3 \%)$ and contained $16.7 \% \mathrm{CP}$ (DM basis), 35\% NDF, $15.8 \%$ starch, and $3.0 \% \mathrm{~K}$ on a DM basis. According to the objectives of the current study, high inclusion of alfalfa silage and supplemental $\mathrm{K}$ for the AS-K diet was intended to increase urinary output (Nennich et al., 2006; Weiss et al., 2009).

The experiment was conducted for $21 \mathrm{~d}$ and during the last $3 \mathrm{~d}$ urine was separated from feces using external urine cups attached to vulva and total urine was collected as described by Weiss et al. (2009). Briefly, urine excreted via urine cups was split into 2 streams. One larger stream was connected to a large container collecting a majority of urine without acid. Another smaller stream was connected to a 4-L container with approximately $150 \mathrm{~mL}$ of $6 \mathrm{~N} \mathrm{HCl}$. The amount of acids in the containers was adjusted to keep urine $\mathrm{pH}$ below 3.0. Urine in both containers was weighed to obtain total daily urine output from individual cows. Subsamples of urine from the small container with acid were collected daily and composited by cow according to daily excretion rates of urine. The composite samples were frozen at $-20^{\circ} \mathrm{C}$ until further analyses. At the same time as TC (3 d), 12 spot urine samples were collected by stimulating the area below the vulva (d 1, 0800, 1400, 2000, and $0200 \mathrm{~h}$; d 2, 1000, 1600, 2200, and $0400 \mathrm{~h}$; d 3, 1200, 1800, 2400, and $0600 \mathrm{~h}$ ). These sampling time points represented every $2 \mathrm{~h}$ in a 24-h cycle. Approximately $100 \mathrm{~g}$ of urine at each time point was subsampled, acidified ( $5 \mathrm{~mL}$ of $6 \mathrm{~N} \mathrm{HCl}$ ), and frozen at $-20^{\circ} \mathrm{C}$ until further analyses. Total urine output was corrected accordingly.

The diets were mixed and fed ad libitum (targeting $5 \%$ refusal) to cows as TMR once a day. Feed offered and refused were measured to obtain feed intake, and feed ingredients (for treatments) and orts (for individual cows) were sampled daily during the TC period and 
composited (within cow) for chemical analyses. Cows were milked twice a day and weighed on 2 consecutive days (d 17 and 18).

\section{Sample Analysis}

Composited feed ingredients and refusals were dried at $55^{\circ} \mathrm{C}$ for $72 \mathrm{~h}$ and ground to pass a $1-\mathrm{mm}$ screen (Wiley Mill, Arthur A. Thomas Co., Philadelphia, PA). Analytical DM of ground samples were determined in a forced-air drying oven at $100^{\circ} \mathrm{C}$ overnight (method 934.01; AOAC International, 2000). Dried (at $55^{\circ} \mathrm{C}$ ) and ground samples were analyzed for $\mathrm{N}$ using the Dumas method (Flash 2000, Thermo Fisher Scientific, Waltham, MA). Individual samples of TC urine (12 samples) and spot urine (144 samples) were thawed and analyzed for creatinine (kit 500701, Cayman Chemical, Ann Arbor, MI) and total N (Flash 2000, Thermo Fisher Scientific).

\section{Calculations and Statistical Analysis}

Daily urine excretion was quantified from TC and also estimated from urinary creatinine concentration in TC urine and spot urine. The creatinine coefficients $(\mathrm{mg} /$ $\mathrm{kg}$ of BW per day) for individual cows were obtained from creatinine concentrations in TC urine (creatinine concentrations $\times$ daily urine output $\div \mathrm{BW}$ ).

To estimate daily urine output, data of individual spot urine samples (e.g., creatinine and $\mathrm{N}$ concentrations) were averaged to represent urine samples obtained with spot sampling frequencies of $12(\mathbf{1 2 T P}$; time points at $2,4,6,8,10,12,14,16,18,20,22$, and $24 \mathrm{~h}$ after feeding), 6 (6TPP; time points at 4, 8, 12, 16, 20, and 24 $\mathrm{h}$ after feeding), 4 (4TP; time points at $6,12,18$, and $24 \mathrm{~h}$ after feeding), or 2 (2TP; time points at 12 and $24 \mathrm{~h}$ after feeding) according to evenly spaced sampling events from feeding time. Urine outputs were estimated from creatinine concentrations obtained from 12TP, $6 \mathrm{TP}, 4 \mathrm{TP}$, or $2 \mathrm{TP}$ using the creatinine coefficient of 29 $\mathrm{mg} / \mathrm{kg}$ of BW (Valadares et al., 1999; Tebbe and Weiss, 2018). Total excretion of urinary $\mathrm{N}$ was calculated by multiplying estimated urine outputs from 12TP, 6TP, $4 \mathrm{TP}$, or $2 \mathrm{TP}$ by the corresponding $\mathrm{N}$ concentrations.

Dietary effects on BW, production, and TC urine outputs were analyzed using the Mixed Procedure of SAS (version 9.4, SAS Institute Inc., Cary, NC) with the fixed effect of diet and the random effect of block, cow within block, and residual error. Descriptive statistics of variables for individual cows in Table 2 were obtained using the Means Procedure of SAS. The comparison of urinary creatinine and $\mathrm{N}$ concentration, urine outputs, and urinary $\mathrm{N}$ excretion between $\mathrm{TC}$ and $12 \mathrm{TP}$ were made using the Mixed procedure of SAS with a model including diet (CS and AS-K), method (TC and 12TP), and diet $\times$ method interaction as fixed effects (12TP as repeated measurements with cow as a subject) and block, cow within block, and residual error as random effects (Table 3). The same model was used to analyze data from different sampling frequencies (12TP, 6TP, $4 \mathrm{TP}$, and 2TP; TP as repeated measurements with cow as a subject using an auto-regressive first-order covariance structure based on lowest Bayesian information criterion). A linear regression analysis was conducted between actual urine outputs (TC) and estimated urine outputs (12TP, 6TP, 4TP, or 2TP) using the REG procedure of SAS (SAS 9.4; SAS Institute Inc.) where adjusted $\mathrm{R}^{2}$ and the root mean squared prediction error were used to evaluate the regression. In addition, the concordance correlation coefficient was calculated using the following equation:

$$
\mathrm{r}_{\mathrm{c}}=2 \mathrm{~S}_{\mathrm{xy}} /\left[\mathrm{S}_{\mathrm{xx}}+\mathrm{S}_{\mathrm{yy}}+\left(\mathrm{X}_{\mathrm{ave}}-\mathrm{Y}_{\mathrm{ave}}\right)^{2}\right],
$$

where $r_{c}=$ concordance correlation coefficient, $S_{x y}=$ covariance between $\mathrm{x}$ and $\mathrm{y}, \mathrm{S}_{\mathrm{xx}}=$ variance for $\mathrm{X}, \mathrm{S}_{\mathrm{yy}}$ $=$ variance for $\mathrm{Y}, \mathrm{X}_{\mathrm{ave}}=$ mean for $\mathrm{X}$, and $\mathrm{Y}_{\text {ave }}=$ mean for Y.

Significant differences among treatments were declared at $P \leq 0.05$. Differences at $0.05<P \leq 0.10$ were considered a trend toward significance. When the main effect of treatment was significant, means were separated by pairwise $t$-test.

\section{RESULTS AND DISCUSSION}

The experimental diets were prepared for cows to produce a wide range of daily urine outputs. Therefore, cows fed AS-K increased $(P<0.01)$ urine outputs compared with that fed CS (Table 1). However, the experimental diets did not affect $(P \geq 0.33)$ DMI, milk yield, and milk composition. Inclusion of alfalfa silage replacing corn silage generally increases urine outputs due to increases in dietary $\mathrm{K}$ content (Weiss et al., 2009; Eriksson and Rustas, 2014). Because dietary K is known to increase urine output, additional $\mathrm{K}$ was included in the AS-K diet for the objectives of the current study. As a result, $\mathrm{K}$ intake was greater $(P<$ 0.01) for cows fed AS-K compared with CS and urine outputs of cows fed AS-K increased $(P<0.01)$ by $44 \%$ compared with that fed CS. However, $\mathrm{N}$ intake, urinary $\mathrm{N}$ excretion, and urinary $\mathrm{N}$ excretion as proportion of $\mathrm{N}$ intake did not differ between cows fed CS and AS-K. Increases in dietary RDP usually increase urinary $\mathrm{N}$ excretion (Nennich et al., 2006). However, an increase in RDP without altering dietary $\mathrm{CP}$ concentration did not affect urinary $\mathrm{N}$ excretion in dairy cows (Tacoma et al., 2017; Savari et al., 2018). In the current study, es- 
Table 1. Effects of feeding the experimental diets on BW, intake, and urine outputs in dairy cows ${ }^{1}$

\begin{tabular}{lcccc}
\hline Item & CS & AS-K & SEM & $P$-value \\
\hline BW, kg & 724.3 & 703.5 & 27.19 & 0.45 \\
Intake & & & & \\
DM, kg/d & 21.8 & 20.9 & 1.09 & 0.48 \\
Water, L/d & 100.1 & 112.0 & 7.78 & 0.12 \\
K, g/d & 333.4 & 618.2 & 28.08 & $<0.01$ \\
N, g/d & 575.2 & 558.1 & 28.96 & 0.61 \\
Milk, kg/d & 27.9 & 30.7 & 3.60 & 0.59 \\
Fat, \% & 4.24 & 4.08 & 0.300 & 0.58 \\
Protein, \% & 3.21 & 3.07 & 0.14 & 0.33 \\
Urine & & & & \\
Output, kg/d & 26.8 & 38.5 & 2.64 & $<0.01$ \\
N, \% & 0.80 & 0.48 & 0.082 & 0.026 \\
N, g/d & 201.5 & 183.2 & 16.24 & 0.35 \\
N, \% of total N intake & 35.3 & 33.0 & 2.94 & 0.60 \\
\hline
\end{tabular}

${ }^{1} \mathrm{CS}=$ a diet with corn silage as major forage (49\% in dietary DM); AS-K = a diet with alfalfa silage as major forage ( $48 \%$ in dietary DM) and supplemental potassium.

${ }^{2}$ Urine from total collection was used for the variables.

timated RDP \% of CP was 10.2 and $11.2 \%$ for CS and AS-K, respectively (NRC, 2001); therefore, the increase in RDP by $1 \%$ unit and numerical decreases in DMI for AS-K versus CS did not affect urinary $\mathrm{N}$ excretion.

Urine outputs of cows varied from 17.9 to $44.3 \mathrm{~kg} / \mathrm{d}$ with an average of $32.6 \mathrm{~kg} / \mathrm{d}$ in the current study (Table 2). Calculated creatinine coefficients (creatinine $\mathrm{mg} / \mathrm{kg}$ of BW per d) for individual cows were also variable from 16.7 to 34.5 with an average of 27.3. In agreement, large variation in the predicted coefficient (20 to 36) was observed by Tebbe and Weiss (2018). The average coefficient (27.3) obtained in the current study is in the range of coefficients used in the literature (24.1 to 29; Valadares et al., 1999; Leonardi et al., 2003; Chizzotti et al., 2008). Among these, the coefficient of 29 has been widely used for spot urine sampling to estimate urine outputs (Lee et al., 2012; Broderick et al., 2015) because the coefficient of 29 was often observed from TC in multiple studies (Valadares et al., 1999; Hristov et al., 2010; Tebbe and Weiss, 2018). However, the large cow-to-cow variation of the coefficient observed in the current study and in other studies (Tebbe and Weiss, 2018) indicates that using a fixed creatinine coefficient for cows (e.g., 29) may lead to inaccurate estimation of urine outputs. Indeed, a study by Andreen et al. (2017) concluded that urinary creatinine concentration as a marker with 29 of the creatinine coefficient was not reliable to accurately estimate urine outputs of dairy cows and our results partially agree with the conclusion by Andreen et al. (2017). Because no other methods are available for estimating urine outputs, the technique needs to be improved to reduce the variation (see the discussion later).

Urinary creatinine and $\mathrm{N}$ concentrations and urine outputs and $\mathrm{N}$ excretion were compared between TC and 12TP (Table 3) where no interaction of diet by method (TC and 12TP) was observed. Urinary output was lower (29.8 vs. $32.6 \mathrm{~kg} / \mathrm{d}$; $P=0.03$ ) for $12 \mathrm{TP}$ (estimated) compared with TC (measured). This underestimation of urine output occurred due to 2 factors: (1) cow-to-cow variation of creatinine coefficients $(\mathrm{mg} / \mathrm{kg}$ of BW per d) as discussed previously and (2) urinary creatinine concentration being greater (75.4 vs. 64.5 $\mathrm{mg} / \mathrm{dL} ; P=0.054)$ for $12 \mathrm{TP}$ compared with TC. However, urinary $\mathrm{N}$ excretion did not differ between $\mathrm{TC}$ and $12 \mathrm{TP}$. The difference in urinary creatinine concentration between 12TP and TC likely occurred due to large diurnal variation of urinary creatinine concentration. The diurnal variation of creatinine concentration in urine was clearly observed in the current study (Figure

Table 2. Descriptive statistics of BW, urine outputs, and creatinine excretion rate of cows used in the experiment $^{1}$

\begin{tabular}{lcccccc}
\hline Item & $\mathrm{N}$ & Mean & SD & Minimum & Median & Maximum \\
\hline BW, kg & 12 & 714 & 64.4 & 577 & 706 & 809 \\
Creatinine, mg/dL & 12 & 64.5 & 26.5 & 36.0 & 56.8 & 121.0 \\
Urine output, kg/d $_{\text {Coefficient }^{2}}^{12}$ & 32.6 & 8.69 & 17.9 & 33.2 & 44.3 \\
\hline
\end{tabular}

${ }^{1}$ Creatinine concentration and urine output were obtained from total collection.

${ }^{2}$ Urinary creatinine excretion, $\mathrm{mg} / \mathrm{kg}$ of BW per d (creatinine concentration $\times$ urine output/BW). 


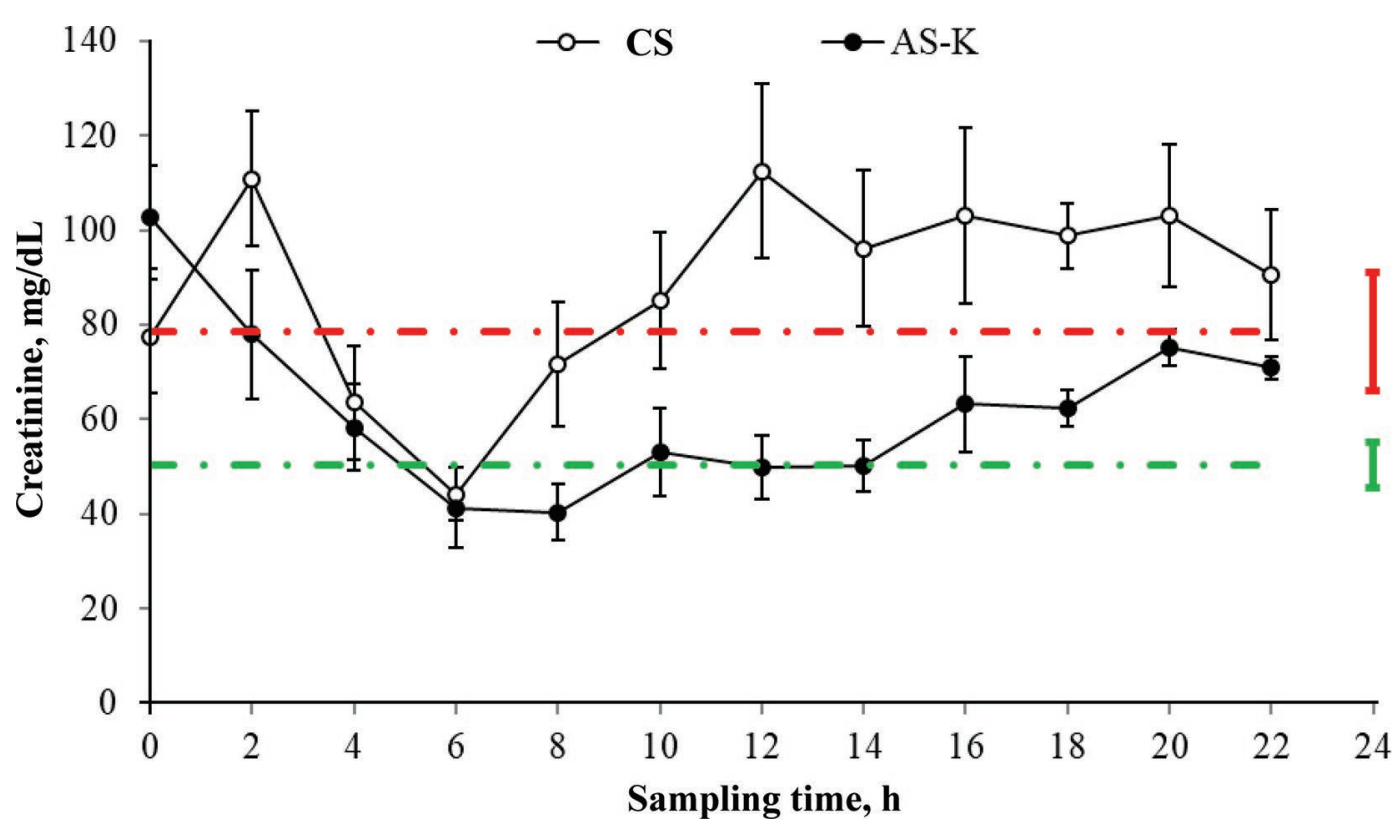

Figure 1. Variation of creatinine concentration (average $\pm \mathrm{SE}$ ) in 12 spot urine samples representing sampling every $2 \mathrm{~h}$ in a 24 -h cycle in dairy cows fed a corn silage-based diet (CS) or alfalfa silage-based diet with supplemental potassium (AS-K) once a day at h 0 . The dotted lines (upper, CS; lower, AS-K) represent the creatinine concentrations with SE in total collection of urine.

1), which is in agreement with other studies (de Groot and Aafjes, 1960; Shingfield and Offer, 1998; George et al., 2006). The pattern of changes in creatinine concentrations in urine over $24 \mathrm{~h}$ was similar between CS and AS-K, where creatinine rapidly decreased until 6 to $8 \mathrm{~h}$ after feeding and then increased. The underestimation of urine outputs with $12 \mathrm{TP}$ may indicate that the sampling frequency of 12 was not enough to have a urine sample that is representative of urine from TC (i.e., creatinine concentration) or spot sampling may not be appropriate to obtain a representative urine sample regardless of sampling frequency. If the former is the issue, sampling of spot urine more than 12 in frequency is not practically feasible. We speculate that the spot sampling procedure (i.e., multiple spot sampling events in an equally spaced interval) may not be appropriate to obtain a urine sample that is representative of TC urine for reasons that are discussed in detail later.

For the purpose of optimizing the frequency of spot urine sampling, individual spot samples were used to reconstitute composite urine samples from various sampling frequencies (i.e., $12 \mathrm{TP}, 6 \mathrm{TP}, 4 \mathrm{TP}$, and $2 \mathrm{TP}$ ) where creatinine and $\mathrm{N}$ concentrations and daily urine outputs and $\mathrm{N}$ excretion among 12TP, 6TP, 4TP, and $2 \mathrm{TP}$ were compared and presented in Table 4 . No interaction of diet by method (frequencies of spot sampling) was observed except for urinary $\mathrm{N}$ excretion $(P=0.03)$. Urinary creatinine concentrations among 12TP, 6TP, $4 \mathrm{TP}$, and $2 \mathrm{TP}$ were different $(P=0.01)$ where urinary creatinine concentration was greater for $2 \mathrm{TP}$ compared with the others without difference among $12 \mathrm{TP}, 6 \mathrm{TP}$, and 4TP. The difference in urinary creatinine con-

Table 3. Urine outputs and $\mathrm{N}$ excretion determined from total collection or spot sampling with 12 sampling frequencies

\begin{tabular}{|c|c|c|c|c|c|c|}
\hline \multirow[b]{2}{*}{ Item } & \multicolumn{2}{|c|}{ Method $^{1}$} & \multirow[b]{2}{*}{ SEM } & \multicolumn{3}{|c|}{$P$-value ${ }^{2}$} \\
\hline & $\mathrm{TC}$ & $12 \mathrm{TP}^{3}$ & & $\mathrm{D}$ & M & $\mathrm{D} \times \mathrm{M}$ \\
\hline Creatinine, mg/dL & 64.5 & 75.4 & 7.87 & 0.02 & 0.054 & 0.78 \\
\hline Urinary $\mathrm{N}, \%$ & 0.64 & 0.68 & 0.062 & 0.02 & 0.31 & 0.98 \\
\hline Urine output, $\mathrm{kg} / \mathrm{d}$ & 32.6 & 29.8 & 2.43 & $<0.01$ & 0.03 & 0.37 \\
\hline Urinary $\mathrm{N}, \mathrm{g} / \mathrm{d}$ & 192.3 & 186.0 & 9.96 & 0.07 & 0.58 & 0.54 \\
\hline
\end{tabular}

${ }^{1} \mathrm{TC}=$ total collection of urine; $12 \mathrm{TP}=$ spot sampling of urine with 12 sampling frequencies.

${ }^{2} \mathrm{D}=$ diet effect; $\mathrm{M}=$ method effect; $\mathrm{D} \times \mathrm{M}=$ interaction of $\mathrm{D}$ and $\mathrm{M}$.

${ }^{3}$ Urinary outputs were estimated with 29 of the coefficient (urinary creatinine excretion, $\mathrm{mg} / \mathrm{d}$ per $\mathrm{kg}$ of BW) for all cows. 
Table 4. Urine outputs and $\mathrm{N}$ excretions estimated from spot sampling with different sampling frequencies

\begin{tabular}{|c|c|c|c|c|c|c|c|c|}
\hline \multirow[b]{2}{*}{ Item } & \multicolumn{4}{|c|}{ Method $^{1,2}$} & \multirow[b]{2}{*}{ SEM } & \multicolumn{3}{|c|}{$P$-value ${ }^{3}$} \\
\hline & $12 \mathrm{TP}$ & $6 \mathrm{TP}$ & $4 \mathrm{TP}$ & $2 \mathrm{TP}$ & & $\mathrm{D}$ & M & $\mathrm{D} \times \mathrm{M}$ \\
\hline Creatinine, $\mathrm{mg} / \mathrm{dL}$ & $75.4^{\mathrm{b}}$ & $76.7^{\mathrm{b}}$ & $74.8^{\mathrm{b}}$ & $85.6^{\mathrm{a}}$ & 8.42 & 0.055 & 0.01 & 0.59 \\
\hline Urinary N, \% & 0.68 & 0.67 & 0.66 & 0.71 & 0.059 & $<0.01$ & 0.28 & 0.79 \\
\hline Urine output, ${ }^{4} \mathrm{~kg} / \mathrm{d}$ & 29.8 & 29.4 & 29.2 & 26.4 & 2.28 & 0.15 & 0.09 & 0.41 \\
\hline Urinary $\mathrm{N}, \mathrm{g} / \mathrm{d}$ & 186.0 & 181.0 & 183.8 & 175.2 & 6.48 & $<0.01$ & 0.10 & 0.03 \\
\hline
\end{tabular}

${ }^{\mathrm{a}, \mathrm{b}}$ Within a row, means without a common superscript letter differ $(P<0.05)$.

${ }^{1} 12 \mathrm{TP}, 6 \mathrm{TP}, 4 \mathrm{TP}$, and $2 \mathrm{TP}=$ spot sampling of urine with $12,6,4$, and 2 sampling frequencies, respectively.

${ }^{2}$ Urinary outputs were estimated with 29 of the coefficient (urinary creatinine excretion, $\mathrm{mg} / \mathrm{d}$ per $\mathrm{kg}$ of BW) for all cows.

${ }^{3} \mathrm{D}=$ diet effect; $\mathrm{M}=$ method effect; $\mathrm{D} \times \mathrm{M}=$ interaction of $\mathrm{D}$ and $\mathrm{M}$.

${ }^{4}$ Diet effect within $12 \mathrm{TP}, P<0.01$; diet effect within $6 \mathrm{TP}, P=0.05$; diet effect within $4 \mathrm{TP}, P=0.07$; diet effect within $2 \mathrm{TP}, P=0.51$.

centration caused a tendency for the estimated urine outputs from $12 \mathrm{TP}, 6 \mathrm{TP}, 4 \mathrm{TP}$, and $2 \mathrm{TP}$ to be different $(P=0.09)$. However, the different frequencies of spot sampling of urine did not affect urine $\mathrm{N}$ concentration and excretion.

Although spot urine sampling is widely used to estimate urine outputs with urinary creatinine concentration as a marker in ruminants, it is surprising that the procedure of spot sampling of urine has not been optimized. For example, Tebbe and Weiss (2018) used a single spot urine sample $(5 \mathrm{~h}$ after feeding) to estimate urine outputs, and Broderick (2003) and Olmos Colmenero and Broderick (2006) collected 2 spot samples of urine (one at $6 \mathrm{~h}$ before feeding and another at $6 \mathrm{~h}$ after feeding). Eight sampling events of spot urine collection have been also conducted (Lee et al., 2012; Giallongo et al., 2017; Morris et al., 2018). It is generally accepted that the errors from diurnal variation of urinary creatinine concentration can be reduced by increasing frequency of spot sampling. The current results indicate that urine samples from 12,6 , and 4 events of spot sampling had similar creatinine and $\mathrm{N}$ concentrations, resulting in similar urine output and $\mathrm{N}$ excretion. However, no dietary effect (CS vs. AS-K) was detected when urine was estimated with $4 \mathrm{TP}$ (see the footnote of Table 4), so the minimum frequency of 6 spot sampling of urine was required in the current study to examine dietary effects on urine outputs (see more discussion later). However, as indicated previously, even the urine sample from $12 \mathrm{TP}$ failed to represent TC urine (creatinine concentration) and underestimated urine outputs compared with TC, indicating that estimation of urine outputs from creatinine using a spot sampling technique is not reliable regardless of frequency of spot sampling. The failure of representation of the spot urine sample to TC urine was due to diurnal variation of urinary creatinine concentration, which occurred due to either diurnal changes in creatinine production in the body and then excretion in urine or diurnal changes in urine volume. Although creatinine excretion rates (coefficient; $\mathrm{mg} / \mathrm{kg}$ of $\mathrm{BW}$ per d) among cows are variable as shown previously, diurnal variation of creatinine production in the body and excretion in urine within cow is likely small. Creatinine is produced from muscle and is rarely reused in the body (Silva et al., 2012), and the production of creatinine occurs at constant rate proportional to the mass of body muscle, resulting in a constant excretion of creatinine in urine (de Groot and Aafjes, 1960; Erb et al., 1977; Chizzotti et al., 2008). Therefore, the large diurnal variation of creatinine concentration in urine could be mainly attributed to diurnal changes in urine volume rather than diurnal changes in creatinine production. Indeed, a constant rate of creatinine excretion (creatinine concentration $\times$ urine volume) was observed from urine samples collected for various time spans during a day (Chizzotti et al., 2008). de Groot and Aafjes (1960) and Shingfield and Offer (1998) found diurnal variation of urine volume in dairy cows, causing diurnal changes in urinary creatinine concentration. In sheep, a similar pattern of diurnal variation of urine volume was observed where urine excretion considerably increased until 8 to $10 \mathrm{~h}$ after feeding and then decreased (Minson and Cowper, 1966). Aland et al. (2002) observed that urinating events were much higher during feeding and milking compared with resting. Therefore, effect of diurnal variation of urine volume on urine outputs estimated from spot sampling was simulated in Table 5 . In this simulation, 12 spot samples of urine (2-h time span) over $24 \mathrm{~h}$ were collected. Diurnal variation of urine volume was assumed according to studies that reported diurnal changes in urine excretion (Minson and Cowper, 1966; Shingfield and Offer, 1998) with modification (see the table footnote for more information). A constant excretion rate of creatinine in urine was assumed. This simulation indicates that creatinine 
concentration in urine samples obtained from spot sampling was greater $(72.8 \mathrm{vs} .63 .4 \mathrm{mg} / \mathrm{dL})$ than that from TC urine due to diurnal variation of urine excretion in spite of the constant rate of creatinine excretion (i.e., coefficient) in urine. This resulted in underestimation of urine output $(27.9$ vs. $32.0 \mathrm{~L} / \mathrm{d})$, which supports the results in the current study. However, this simulation does not account for the following factors: (1) cow-to-cow and day-to-day variations of diurnal pattern of urine excretion (Shingfield and Offer, 1998) and (2) changes in eating patterns (feed consumption and water intake rates) that can affect diurnal pattern of urine excretion. Therefore, more studies are needed to confirm the conclusion and simulation. An interaction of diet by method was observed for $\mathrm{N}$ excretion. This occurs because $\mathrm{N}$ excretion for 2TP compared with $12 \mathrm{TP}, 6 \mathrm{TP}$, and $4 \mathrm{TP}$ was much lower in cows fed AS$\mathrm{K}$, whereas $\mathrm{N}$ excretion among methods was similar in cows fed CS. Urinary $\mathrm{N}$ concentration among methods within diet was similar $(P>0.05)$, but the estimated urine outputs was lower for $2 \mathrm{TP}$ vs. $12 \mathrm{TP}, 6 \mathrm{TP}$, and $4 \mathrm{TP}$ where the degree of the decrease was much greater for AS-K compared with CS. This also suggests that the reliability of urine outputs estimated with $2 \mathrm{TP}$ was much lower compared with more frequent spot sampling.

It is worth noting that neither significant effect of method nor interaction between diet and method for urinary $\mathrm{N}$ concentration was observed in the current study. This suggests that urinary $\mathrm{N}$ concentration is relatively constant over $24 \mathrm{~h}$ compared with creatinine concentration. Diurnal variation of urine volume and blood $\mathrm{N}$ available for urinary excretion is the function of intake, meaning that the patterns of their diurnal changes are similar (i.e., increasing urine volume and $\mathrm{N}$ available for excretion after feeding and then decreasing gradually). This likely results in relatively consistent $\mathrm{N}$ concentration in urine throughout the day. However, creatinine production and excretion is independent of intake with large diurnal variation in urine volume, causing diurnal variation of urinary creatinine concentration.

Although urinary creatinine with a spot sampling of urine underestimated urine output, leading to unreliability, it is likely that this technique is still valid for successful detection and identification of urine output altered by dietary treatments. Urine outputs estimated from spot sampling had a strong linear relationship with urine output measured (TC; Table 6 and Figure 2 ). Increasing the frequency of spot sampling improved precision and accuracy of the regression between urine estimated and measured according to adjusted $\mathrm{R}^{2}(0.23$ to 0.84$)$, root mean square prediction error $(7.6$ to $3.6)$, and concordance correlation coefficient ( 0.42 to $0.86)$, where $12 \mathrm{TP}, 6 \mathrm{TP}$, and $4 \mathrm{TP}$ may be acceptable to identify urine outputs altered by dietary treatments.

Table 5. A simulation of urine outputs estimated from spot sampling affected by diurnal variation of urine excretion

\begin{tabular}{lccc}
\hline Hours after feeding ${ }^{1}$ & Urine volume, ${ }^{2} \mathrm{~kg}$ & $\begin{array}{c}\text { Creatinine excreted in urine, }{ }^{3} \\
\text { mg in each time span }(2 \mathrm{~h})\end{array}$ & $\begin{array}{c}\text { Creatinine, }{ }^{4} \mathrm{mg} / \mathrm{dL} \text { of spot sample } \\
(2-\mathrm{h} \text { time span) }\end{array}$ \\
\hline 0 to 2 & 2 & 1,692 & 84.6 \\
2 to 4 & 4 & 1,692 & 42.3 \\
4 to 6 & 6 & 1,692 & 28.2 \\
6 to 8 & 4 & 1,692 & 42.3 \\
8 to 10 & 2 & 1,692 & 56.4 \\
10 to 12 & 2 & 1,692 & 84.6 \\
12 to 14 & 2 & 1,692 & 84.6 \\
14 to 16 & 2 & 1,692 & 84.6 \\
16 to 18 & 2 & 1,692 & 84.6 \\
18 to 20 & 3 & 1,692 & 84.6 \\
20 to 22 & 2 & 1,692 & 84.6 \\
22 to 24 & 2 & 1,692 & 84.6 \\
Total & 32 & 20,300 & \\
Creatinine concentration in TC urine, ${ }^{5} \mathrm{mg} / \mathrm{dL}$ & & 63.4 \\
Creatinine concentration in composite $\mathrm{urine}$ from spot sampling, ${ }^{6} \mathrm{mg} / \mathrm{dL}$ & & 72.8 \\
Urine output from TC, $\mathrm{kg} / \mathrm{d}$ & & & 32.0 \\
Urine output estimated from spot sampling, ${ }^{7} \mathrm{~kg} / \mathrm{d}$ & & 27.9
\end{tabular}

\footnotetext{
${ }^{1}$ Simulated urine collection in every 2 -h time span over $24 \mathrm{~h}$.

${ }^{2}$ Simulated diurnal pattern of urine excretion according to the literature (Minson and Cowper, 1966; Shingfield and Offer, 1998) with modification (average urine output of $32 \mathrm{~kg}$ observed in the current study and diurnal changes in urine excretion for the urine output were used).

${ }^{3}$ Creatinine excretion rate $(\mathrm{mg} / \mathrm{kg}$ of $\mathrm{BW}$ per $\mathrm{d})$ of 29 was used with $700 \mathrm{~kg}$ of a cow (i.e., $846 \mathrm{mg}$ of creatinine excretion per h).

${ }^{4}$ Column $4=$ column $3 \div$ column $2 \div 10$.

${ }^{5}$ Daily creatinine excretion $(20,300) \div$ daily urine output $(32) . \mathrm{TC}=$ total collection.

${ }^{6}$ The average of values in column 4 .

${ }^{7} 29 \times 700(\mathrm{BW}) \div(72.8 \times 10)$.
} 
Table 6. Relationships between urine outputs estimated from spot sampling with different sampling frequencies and urine outputs measured from total collection

\begin{tabular}{|c|c|c|c|c|c|c|c|c|}
\hline Item $^{1}$ & \multicolumn{2}{|c|}{ Parameter $^{2}$} & \multicolumn{3}{|c|}{$P$-value ${ }^{3}$} & $\mathrm{R}^{2} \operatorname{adj}^{4}$ & $\mathrm{RMSPE}^{5}$ & $\mathrm{CCC}$ \\
\hline $12 \mathrm{TP}$ & $2.6(4.2)$ & $1.0(0.1)$ & 0.55 & $<0.01$ & 0.95 & 0.84 & 3.6 & 0.86 \\
\hline $4 \mathrm{TP}$ & $-1.4(7.4)$ & $1.2(0.2)$ & 0.85 & $<0.01$ & 0.52 & 0.69 & 5.1 & 0.71 \\
\hline $2 \mathrm{TP}$ & $16.1(8.2)$ & $0.6(0.3)$ & 0.08 & 0.06 & 0.24 & 0.23 & 7.6 & 0.42 \\
\hline
\end{tabular}

${ }^{1} 12 \mathrm{TP}, 6 \mathrm{TP}, 4 \mathrm{TP}$, and $2 \mathrm{TP}=$ spot sampling of urine with $12,6,4$, and 2 sampling frequencies, respectively.

${ }^{2}$ Int $=$ intercept.

${ }^{3}$ Int $=$ intercept vs. $0 ;$ slope $\_0=$ slope vs. $0 ;$ slope_ $1=$ slope vs. 1 .

${ }^{4}$ Adjusted $\mathrm{R}^{2}$.

${ }^{5}$ Root mean square prediction error.

${ }^{6}$ Concordance correlation coefficient.

This is in agreement with the accuracy evaluated by slopes and intercepts between urine outputs estimated and measured. The regression between TC and 12TP, $6 \mathrm{TP}$, or $4 \mathrm{TP}$ had an intercept being not different from 0 and slope being different from 0 but not different from 1. However, further statistical examination of dietary effect within method in Table 4 indicated that urine outputs were not different $(P \geq 0.07$; footnote in Table 4) between diets (CS vs. AS-K) when urine outputs were estimated with 4TP and 2TP. Therefore, our conclusion is that urinary creatinine as a marker with spot sampling of urine can be successfully used to examine dietary effects on urine outputs and a spot urine sampling frequency of at least 6 (equally spaced interval in a 24 -h cycle) was optimal to obtain reliable results in the current study.

According to our results and evidence in the literature above, we concluded that urinary creatinine as a marker with a multiple spot sampling technique may not be reliable to accurately estimate urine outputs of dairy cows, although dietary effects on urine outputs can be successfully evaluated using this technique. This unreliability has been also raised by other studies as well (Shingfield and Offer, 1998; Andreen et al., 2017). As discussed previously, the potential inaccuracy is likely attributed to (1) variable creatinine coefficients among cows and (2) diurnal variation of creatinine concentration within cow. To improve the accuracy, cow-to-cow variation of creatinine coefficients needs to be reduced by increasing the number of cows per treatment because an average of the coefficients among cows is generally consistent $\left(29 \mathrm{mg}\right.$ per $\mathrm{kg}$ of $\left.\mathrm{BW} \cdot \mathrm{d}^{-1}\right)$. In addition, the lean tissue mass rather than $\mathrm{BW}$ of cows can be used to lower the variation when creatinine coefficients are calculated. Because creatinine production is proportional to the mass of body muscle (Narayanan and Appleton, 1980), the use of BW to obtain a creatinine coefficient may overestimate urine outputs of cows, especially fat cows (e.g., cows at different lactation stages). Therefore, using BW corrected for fatness of cows (e.g., BCS) may have potential to improve the accuracy of estimating urine outputs. In addition, the error from diurnal variation of urinary creatinine concentration within cow needs to be reduced to improve the accuracy of estimating urine. A single spot sampling of urine at $10 \mathrm{~h}$ after feeding may have potential to obtain a urine sample that is more representative of $\mathrm{TC}$ urine in terms of creatinine concentration compared with a sample from multiple spot sampling (i.e., 12TP). Because of the diurnal variation of creatinine concentration in urine (Figure 1), urinary creatinine concentration at about $10 \mathrm{~h}$ after feeding was similar to that in TC urine regardless of dietary treatments. This is in line with results in the literature. Shingfield and Offer (1998) observed that creatinine concentration in urine collected at 8 to $10 \mathrm{~h}$ after feeding was similar to that in TC urine regardless of feeding treatments (component vs. TMR feeding). In sheep, the volume of urine excreted at 10 to $16 \mathrm{~h}$ after feeding was close to an average rate of urine excretion (g/h; Minson and Cowper, 1966). However, this should be validated by studies with large number of animals and various dietary conditions. In the current study, when urine output estimated from a single spot sample at $10 \mathrm{~h}$ after feeding was compared with actual urine output (TC), no differences in creatinine concentration, urinary $\mathrm{N}$ concentration, urine output, and urinary $\mathrm{N}$ excretion were observed $(P \geq 0.36$; data not shown) without an interaction between diet and method. However, the lack of difference between a single spot sampling at $10 \mathrm{~h}$ and TC may have occurred because SEM of urinary creatinine concentration and urine output from single spot sampling was much greater than those from multiple spot sampling (data not shown). In addition, a linear regression analysis indicates that root mean squared error was much higher (5.8 vs. 3.6 ; data 


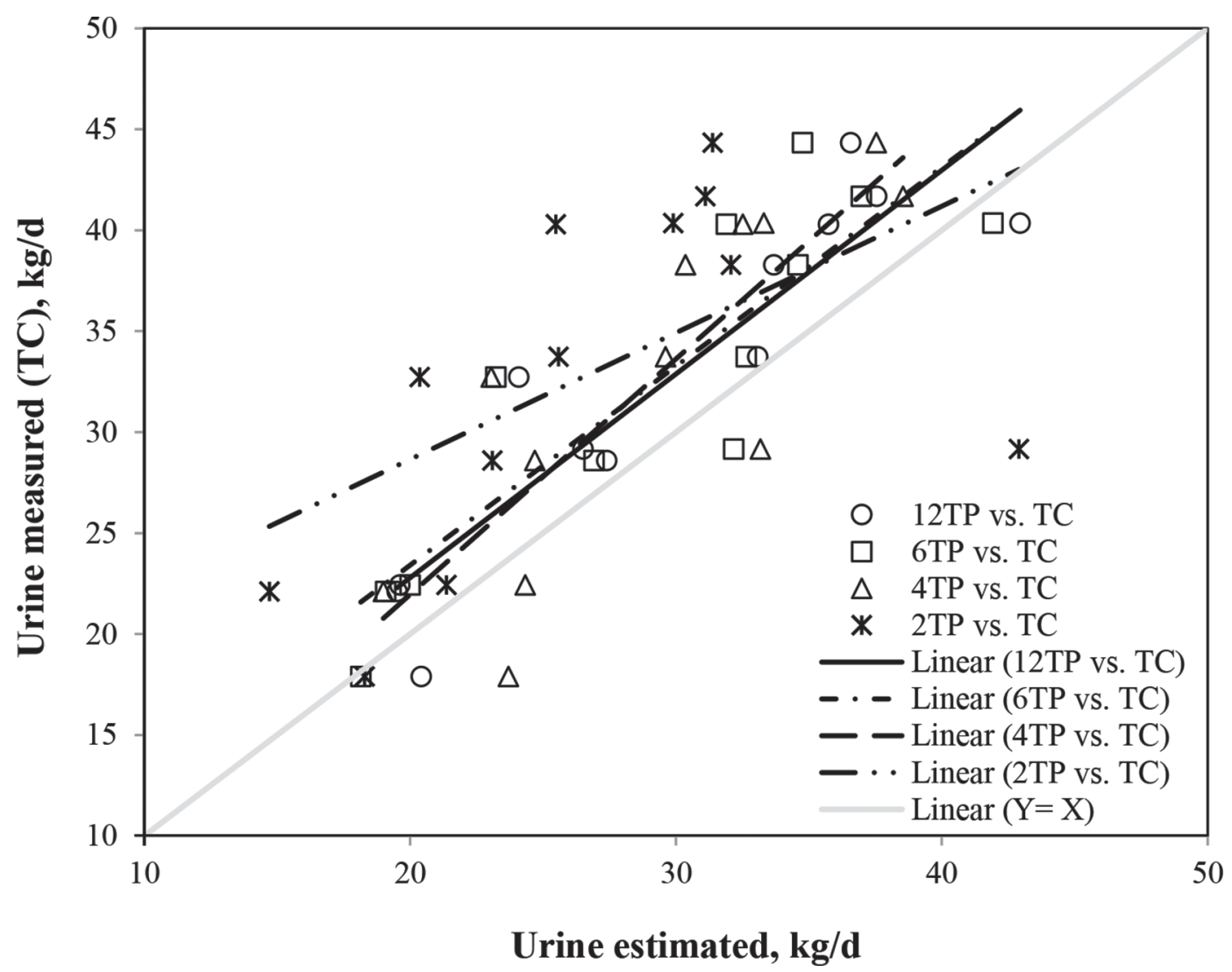

Figure 2. Relationship between urine outputs estimated from 12 spot samplings of urine and urine outputs measured from total collection $(\mathrm{TC}) . \mathrm{TP}=$ time points.

not shown) for the 10-h spot urine sample compared with $12 \mathrm{TP}$. This suggests that cow-to-cow variation was much larger when the single spot sample was used. However, this variation can be decreased by single spot urine sampling for multiple days from individual cows, which needs further validation.

\section{CONCLUSIONS}

In the current experimental conditions (e.g., diets and production of animals), urine spot samples from the frequency of 12 sampling events underestimated urine outputs compared with urine output from TC. This underestimation occurred due to cow-to-cow variation of creatinine coefficients and large diurnal variation of urinary creatinine concentration. The large diurnal variation of urinary creatinine concentration occurred due to diurnal changes in urine volume rather than diurnal changes in creatinine production. A regression analysis indicated that although urine output was underestimated using urinary creatinine with spot sampling of urine, this technique was still useful to examine dietary effects on urine outputs. To obtain a reliable comparison of urine outputs between diets, a spot urine sampling frequency of at least 6 (equally spaced time interval in a $24-\mathrm{h}$ cycle) was required in the current study.

\section{ACKNOWLEDGMENTS}

The authors thank the Krauss Dairy Farm staff for care of the experimental animals (The Ohio State University, Wooster). The experiment was partially supported by Animal Sciences in The Ohio State University and Hatch funds administered by the USDA (Washington, DC).

\section{REFERENCES}

Aland, A., L. Lidfors, and I. Ekesbo. 2002. Diurnal distribution of dairy cow defecation and urination. Appl. Anim. Behav. Sci. 78:43-54.

Andreen, D. M., E. Liu, and M. J. VandeHaar. 2017. Estimating urinary nitrogen using creatinine in cows fed adequate and protein deficient diets. J. Dairy Sci. 100(Suppl. 1):187. (Abstr.)

AOAC International. 2000. Official Methods of Analysis. Vol. 1 and 2. 17th ed. AOAC International, Gaithersburg, MD.

Benefield, B. C., R. A. Patton, M. J. Stevenson, and T. R. Overton. 2009. Evaluation of rumen-protected methionine sources and pe- 
riod length on performance of lactating dairy cows within Latin squares. J. Dairy Sci. 92:4448-4455.

Broderick, G. A. 2003. Effects of varying dietary protein and energy levels on the production of lactating dairy cows. J. Dairy Sci. 86:1370-1381.

Broderick, G. A., A. P. Faciola, and L. E. Armentano. 2015. Replacing dietary soybean meal with canola meal improves production and efficiency of lactating dairy cows. J. Dairy Sci. 98:5672-5687.

Broderick, G. A., and S. M. Reynal. 2009. Effect of source of rumendegraded protein on production and ruminal metabolism in lactating dairy cows. J. Dairy Sci. 92:2822-2834.

Chizzotti, M. L., S. D. Valadares, R. F. D. Valadares, F. H. M. Chizzotti, and L. O. Tedeschi. 2008. Determination of creatinine excretion and evaluation of spot urine sampling in Holstein cattle. Livest. Sci. 113:218-225.

de Groot, T., and J. H. Aafjes. 1960. On the constancy of creatinine excretion in the urine of the dairy cow. Br. Vet. J. 116:409-418.

Erb, R. E., A. H. Surve, R. D. Randel, and H. A. Garverick. 1977. Urinary creatinine as an index of urinary-excretion of estrogen in cows prepartum and postpartum. J. Dairy Sci. 60:1057-1063.

Eriksson, T., and B. O. Rustas. 2014. Effects on milk urea concentration, urine output, and drinking water intake from incremental doses of potassium bicarbonate fed to mid-lactation dairy cows. J. Dairy Sci. 97:4471-4484.

George, S. K., M. T. Dipu, U. R. Mehra, A. K. Verma, and P. Singh. 2006. Influence of level of feed intake on concentration of purine derivatives in urinary spot samples and microbial nitrogen supply in crossbred bulls. Asian-australas. J. Anim. Sci. 19:1291-1297.

Giallongo, F., M. T. Harper, J. Oh, C. Parys, I. Shinzato, and A. N. Hristov. 2017. Histidine deficiency has a negative effect on lactational performance of dairy cows. J. Dairy Sci. 100:2784-2800.

Hristov, A. N., G. Varga, T. Cassidy, M. Long, K. Heyler, S. K. R. Karnati, B. Corl, C. J. Hovde, and I. Yoon. 2010. Effect of Saccharomyces cerevisiae fermentation product on ruminal fermentation and nutrient utilization in dairy cows. J. Dairy Sci. 93:682-692.

Lee, C., A. N. Hristov, T. W. Cassidy, K. S. Heyler, H. Lapierre, G. A. Varga, M. J. de Veth, R. A. Patton, and C. Parys. 2012. Rumenprotected lysine, methionine, and histidine increase milk protein yield in dairy cows fed a metabolizable protein-deficient diet. J. Dairy Sci. 95:6042-6056.

Leonardi, C., M. Stevenson, and L. E. Armentano. 2003. Effect of two levels of crude protein and methionine supplementation on performance of dairy cows. J. Dairy Sci. 86:4033-4042.

Minson, D. J., and J. L. Cowper. 1966. Diurnal variations in the excretion of faeces and urine by sheep fed once daily or at hourly intervals. Br. J. Nutr. 20:757-764.

Morris, D. L., S. H. Kim, P. J. Kononoff, and C. Lee. 2018. Continuous 11-week feeding of reduced-fat distillers grains with and without monensin reduces lactation performance of dairy cows. J. Dairy Sci. 101:5971-5983.

Morris, D. L., L. R. Rebelo, D. A. Phyllis, and C. Lee. 2018. Validating intrinsic markers and optimizing spot sampling frequency to estimate fecal outputs. J. Dairy Sci. 101:7980-7989.

Narayanan, S., and H. D. Appleton. 1980. Creatinine-A review. Clin. Chem. 26:1119-1126.

Nennich, T. D., J. H. Harrison, L. M. VanWieringen, N. R. St-Pierre, R. L. Kincaid, M. A. Wattiaux, D. L. Davidson, and E. Block. 2006. Prediction and evaluation of urine and urinary nitrogen and mineral excretion from dairy cattle. J. Dairy Sci. 89:353-364.

NRC. 2001. Nutrient Requirements of Dairy Cattle. 7th rev. ed. Natl. Acad. Sci. Washington, DC.

Olmos Colmenero, J. J., and G. A. Broderick. 2006. Effect of dietary crude protein concentration on milk production and nitrogen utilization in lactating dairy cows. J. Dairy Sci. 89:1704-1712.

Savari, M., M. Khorvash, H. Amanlou, G. R. Ghorbani, E. Ghasemi, and M. Mirzaei. 2018. Effects of rumen-degradable protein: Rumen-undegradable protein ratio and corn processing on production performance, nitrogen efficiency, and feeding behavior of Holstein dairy cows. J. Dairy Sci. 101:1111-1122.

Shingfield, K. J., and N. W. Offer. 1998. Evaluation of the spot urine sampling technique to assess urinary purine derivative excretion in lactating dairy cows. Anim. Sci. 66:557-568.

Silva, L. F. C. E., S. D. Valadares, M. L. Chizzotti, P. P. Rotta, L. F. Prados, R. F. D. Valadares, D. Zanetti, and J. M. D. Braga. 2012. Creatinine excretion and relationship with body weight of Nellore cattle. Rev. Bras. Zootec. 41:807-810.

Tacoma, R., J. Fields, D. B. Ebenstein, Y. W. Lam, and S. L. Greenwood. 2017. Ratio of dietary rumen degradable protein to rumen undegradable protein affects nitrogen partitioning but does not affect the bovine milk proteome produced by mid-lactation Holstein dairy cows. J. Dairy Sci. 100:7246-7261.

Tebbe, A. W., and W. P. Weiss. 2018. Evaluation of creatinine as a urine marker and factors affecting urinary excretion of magnesium by dairy cows. J. Dairy Sci. 101:5020-5032.

Valadares, R. F. D., G. A. Broderick, S. C. Valadares, and M. K. Clayton. 1999. Effect of replacing alfalfa silage with high moisture corn on ruminal protein synthesis estimated from excretion of total purine derivatives. J. Dairy Sci. 82:2686-2696.

Weiss, W. P. 2012. Use of a corn milling product in diets for dairy cows to alleviate milk fat depression. J. Dairy Sci. 95:2081-2090.

Weiss, W. P., L. B. Willett, N. R. St-Pierre, D. C. Borger, T. R. McKelvey, and D. J. Wyatt. 2009. Varying forage type, metabolizable protein concentration, and carbohydrate source affects manure excretion, manure ammonia, and nitrogen metabolism of dairy cows. J. Dairy Sci. 92:5607-5619. 